\title{
An Agent-based Dynamic Information Network for Supply Chain Management
}

\author{
H J Ahn and H Lee
}

One of the main research issues in supply chain management is to improve the global efficiency of supply chains. However, the improvement efforts often fail because supply chains are complex, are subject to frequent changes, and collaboration and information sharing in the supply chains are often infeasible. This paper presents a practical collaboration framework for supply chain management wherein multi-agent systems form dynamic information networks and coordinate their production and order planning according to synchronized estimation of market demands. In the framework, agents employ an iterative relaxation contract net protocol to find the most desirable suppliers by using data envelopment analysis. Furthermore, the chain of buyers and suppliers, from the end markets to raw material suppliers, form dynamic information networks for synchronized planning. This paper presents an agent-based dynamic information network for supply chain management and discusses the associated pros and cons.

\section{Introduction}

With the advancement of global markets, rapid development of technology, and the shortening life cycle of products, the importance of supply chain management cannot be stressed too highly. A supply chain is a valuecreating network consisting of suppliers, warehouses, manufacturers, wholesalers, and retailers through which material and products are acquired, transformed, and delivered to consumers in markets. One of the most difficult but critical issues in supply chain management is to improve the efficiency of supply chains from the perspective of the whole supply chain, not individual companies. More specifically, the formation, optimisation and minimizing the bullwhip effect (the magnification of demand fluctuations as orders move up the supply chain.) [4] are considered critical issues for efficient supply chain management [10][17].

These issues emerge due to the following characteristics of supply chains. First, they are subject to frequent changes. New suppliers, new buyers, and new types of products appear frequently, and the supply chain networks should be adjusted according to the changes by adopting new members dynamically. Second, although it is well-known that sharing information among supply chain members can lead to improved efficiency, information sharing is not always possible, often because of the limitations in information systems, too frequent changes in partnerships, or strategic reasons resulting from game-theoretic behaviour of companies. Information sharing is especially difficult among companies that are remotely located in the supply chain topology in contrast to neighbouring companies. Third, controlling and coordinating production and orders of supply chain members by a single company or a decision-making unit is in many cases infeasible, because supply chain members are usually independent companies.

This paper proposes an agent-based dynamic information network for supply chain management (ADINS). With the framework, agent systems adapt to changes in supply chain configuration by selecting efficient suppliers with an iterative relaxation contract net protocol and the data envelopment analysis (DEA) [1] technique. Once a supply chain is configured, an information network (reflecting the practical difficulty of information sharing among remotely located companies) is constructed by local collaboration among agents. The information network is used for synchronized estimation of market demands and planning of production and orders, which minimizes a bullwhip effect in the supply chain.

This paper is organized as follows: Section 2 reviews related works on the issues of applying multi-agent technology to supply chain management and information sharing in supply chains. Section 3 introduces ADINS and explains its components and associated processes. Finally, Section 4 discusses the pros and cons of ADINS and concludes this paper. 


\section{Literature review}

Multi-agent technology, which is based on distributed artificial intelligence (DAI) and has been rigorously researched since the early 1990s, is regarded as one of the most promising technologies for supply chain management $[2][13][15][16][18][1]$. First, the autonomous nature of independent agents is suitable for supply chain management where a single company cannot govern the whole supply chain coordination. Second, the 'intelligence' of each agent, which is supported by many tools and techniques from artificial intelligence, can help the various planning activities in supply chain management. Third, agents can form dynamic collaboration network for turbulent supply chains through contracts or negotiations that are supported by agent interaction protocols.

The studies on agent-based supply chain management can be classified into three categories. The studies in the first category show how multi-agent technology can improve the operational efficiency of supply chains by reducing costs and improving performance. For example, Pontrandolfo et al. [14] present a global supply chain management framework utilizing reinforcement learning technique combined with Markov decision theory. Fox et al. [9] present an integrated agent-based supply chain model that can adapt to stochastic events such as breakdown of plants. The studies in the second category are concerned with the issue of dynamic formation of an efficient supply chain network to improve its adaptability and efficiency. For example, Chen et al. [4] describe an approach that uses subcontract auctions to form dynamic and efficient supply chains. Mondal and Tiwari [12] suggest a mobile-agent system wherein mobile agents migrate to the systems of partner companies to find and evaluate potential partners for supply chain formation. The studies in the third category focus on the suggestion of effective agent-based architectures for supply chain management. Shen et al. [16] analyse the advantages of agent technology and propose a multi-agent architecture and an infrastructure for an Internet-enabled collaborative enterprise. Swaminathan et al. [18] propose a component-based architecture for agentbased supply chains which allows the easier simulation and development of supply chain management systems.

The studies reviewed above demonstrate the advantages of multi-agent technology for modelling supply chain components and interactions between the components via specific communication protocols for negotiation and contracts. However, they are deficient in providing a practical agent architecture and collaboration mechanisms reflecting the difficulties and constraints in global information sharing and optimised negotiations in a supply chain, which are the main issues this paper tries to resolve using multi-agent technology.

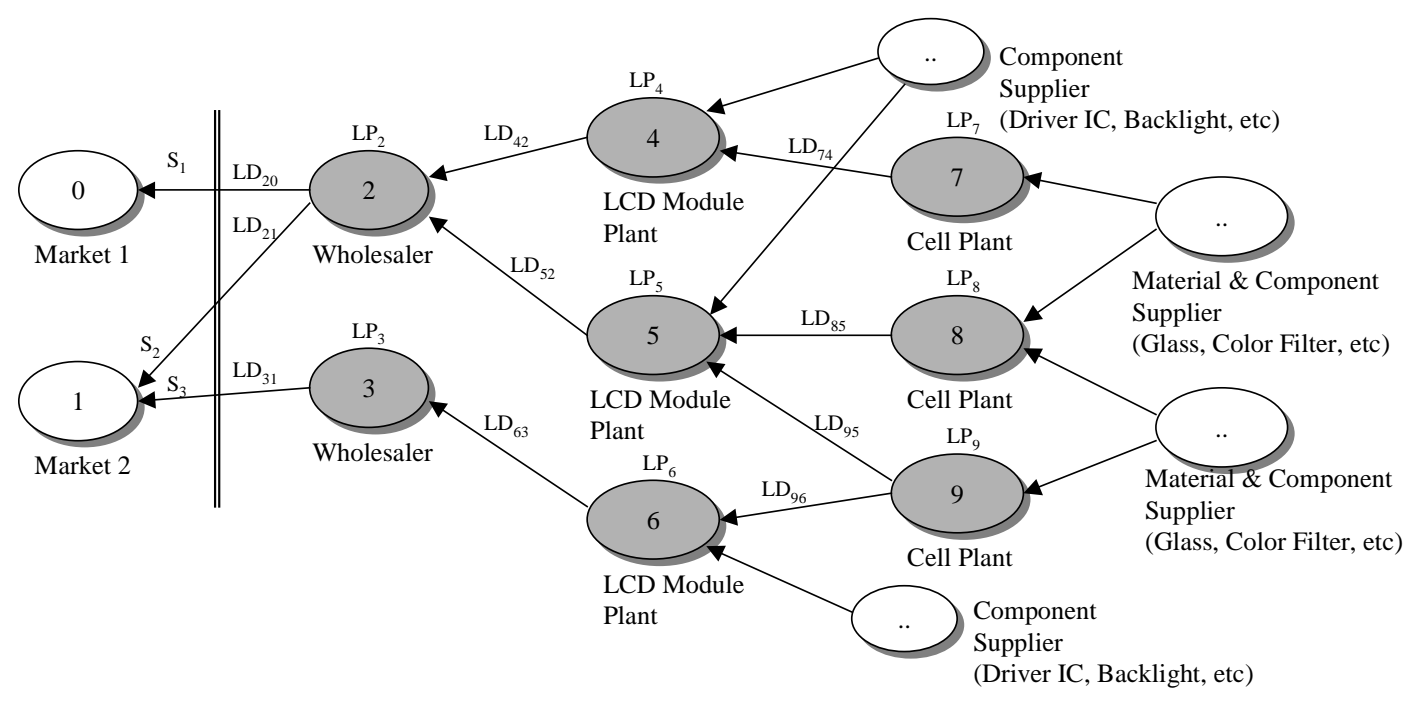

Fig 1 An example supply chain model of a LCD manufacturing company

\section{ADINS: AGENT-BASED DYNAMIC INFORMATION NETWORK FOR SUPPLY CHAIN MANAGEMENT}

\subsection{Overview of ADINS}

Fig 1 shows an example supply chain of a Korean TFT LCD manufacturing company which is used throughout this paper. TFT LCD modules are widely used for display devices such as mobile phones, PDAs (Personal Digital Assistants), and notebook PCs. In the supply chain, there are two end markets where demand is generated, and new suppliers can appear and replace old ones. For a company 
like Cell Plant 7 demand is distorted along the multiple paths from the markets to the company due to bullwhip effects and accumulation of erroneous estimations.

ADINS takes a simple but practical approach to address this problem. In an ADINS, agents autonomously form an information network by only local collaboration and information sharing. Using the network, they perform order and production planning in a synchronized way without any central controlling entities. For this, we assume that agents are able to observe market demands directly rather than relying on the possibly distorted demand figures that are received by their companies. By doing this, ADINS is able to reduce bullwhip effects, cut inventory costs, and improve service quality such as fill rates.

Fig 2 shows the architecture of an ADINS. To increase the practicality of ADINS, all the interactions among participating agents in a supply chain are based on the specifications from FIPA [5] which produces standards for the interoperation of heterogeneous software agents. The agents use the interaction protocols defined by FIPA to communicate with each other via asynchronous message exchanges. The message structure also has been defined by the FIPA ACL (Agent Communication Language) format. The messages are exchanged using Internet protocols such as TCP/IP, HTTP, and SMTP.
Each company in a supply chain is assigned four agents: MEA (Market Estimation Agent) that directly observes and estimates market demands; OPA (Order \& Production Agent) for handling orders and processing production; SSA (Supply chain Structure Agents) for constructing information networks; and PSA (Planning \& Scheduling Agent) for planning and scheduling orders and production.

Only local collaboration among the agents of neighbouring companies is used reflecting the practical difficulty of global information sharing. There is also a directory facilitator (DF) agent in an ADINS to provide yellow pages services to the agents in each company so that they can find each other to make contracts for the supply of materials or products. The detailed behaviour of each agent is described later in this paper.

The interactions between agents in different companies are performed through two phases. In the first phase, the agents build updated supplier-buyer relationship so that changes in the markets can be continuously reflected in the supply chain. In this phase, buyer agents in an ADINS use an iterative relaxation Contract Net protocol and DEA to select efficient buyers and make contracts. In the second phase, an information network is constructed and actual activities for the management of the information network including manufacturing and ordering are performed.

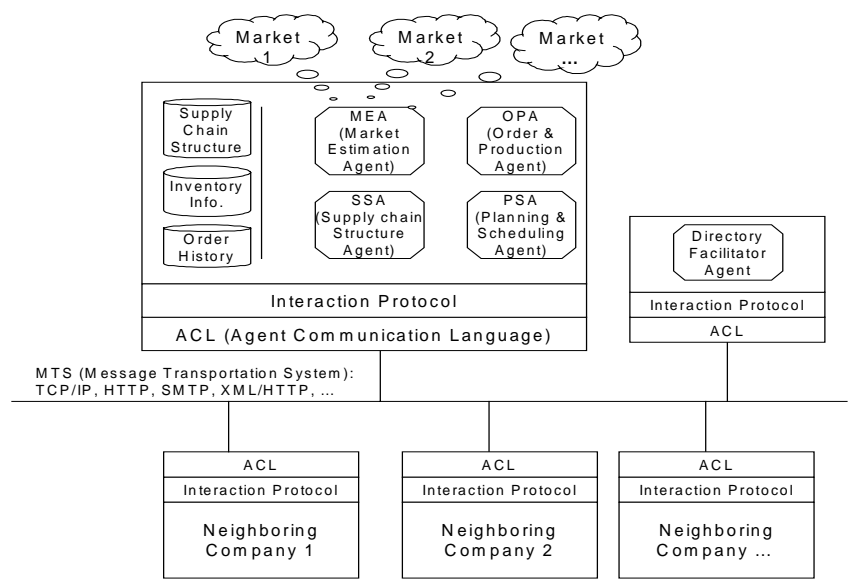

Fig 2 The architecture of ADINS

\subsection{Formation of Buyer-Supplier Relationship with Iterative Relaxation Contract Net and DEA}

Most optimisation approaches to supply chain management are mainly restricted to simple supply chain models with a two or three tier architecture, which makes it difficult to generalise their result to practical and complex supply chains (see [1] as an example). This is also true for the formation of supplier-buyer relationships in a supply chain. When a buyer has to select suitable suppliers from a large number of candidates, it is difficult to estimate how an attribute of the suppliers may ultimately relate to the performance of the buyer or the whole supply chain, especially when there are multiple attributes for which there are no optimal or semi-optimal decision support rules.

For the above reasons, ADINS uses Data Envelopment Analysis for selecting relatively efficient suppliers. Although an optimisation technique may not work in complex environments, DEA can filter out relatively inefficient suppliers and provide a small number of efficient ones. 
DEA uses the linear programming (LP) model shown below to evaluate the relative-efficiency of all decision units [1], the suppliers in ADINS. In the model, $X_{i}$ is the vector for input variables in supplier $i, Y_{i}$ the vector for output variables in supplier $i$, and $\lambda_{i}$ the weight of $i^{\text {th }}$ supplier with which other suppliers are combined and compared to the target supplier with input vector $X_{o}$ and output vector $\mathrm{Y}_{\mathrm{o}}$. For example, if there are $\mathrm{n}$ suppliers, the
LP problem is solved for each of the $\mathrm{n}$ suppliers and the value of $\theta$ in the solution represents the relative efficiency of each supplier. For efficient suppliers, the value of $\theta$ becomes 1 , and for relatively inefficient ones, it goes below 1.

$$
\begin{aligned}
& \operatorname{Min} \theta \\
& \text { s.t. } \sum \lambda_{i} X_{i} \leq \theta \quad X_{0} \\
& \quad \sum \lambda_{i} Y_{i} \geq Y_{0}
\end{aligned}
$$

Table 1 Hypothetical suppliers and their relative efficiency scdiresicalculated with two output measures

\begin{tabular}{ccccc}
\hline Supplier & Capacity & $\begin{array}{c}\text { Price Advantage }= \\
\text { MaxPrice }- \text { Price of } \\
\text { Supplier i }\end{array}$ & $\begin{array}{c}\text { Efficiency Score } \\
\theta \times 100 \%\end{array}$ & Benchmark \\
\hline S1 & 53 & 40 & $100.00 \%$ & - \\
\hline S2 & 62 & 20 & $82.00 \%$ & $6(0.46) 7(0.36)$ \\
\hline S3 & 31 & 30 & $70.27 \%$ & $1(0.51) 5(0.19)$ \\
\hline S4 & 41 & 40 & $93.51 \%$ & $1(0.68) 5(0.26)$ \\
\hline S5 & 20 & 50 & $100.00 \%$ & - \\
\hline S6 & 80 & 20 & $100.00 \%$ & - \\
\hline S7 & 70 & 30 & $100.00 \%$ & - \\
\hline
\end{tabular}

For example, consider the seven hypothetical suppliers in Table 1 with two performance measures, the processing capacity and the price advantage of each supplier. The set of relatively efficient suppliers constitute of a convex plane (or convex line in a two-dimensional case) called efficiency frontier as shown in Fig 3 and the other suppliers are located under the plane. The result of DEA for the suppliers is also shown in Table 1, where suppliers with $100 \%$ efficiency are those located on the efficiency frontier. The benchmark value for an inefficient supplier represents the point where the extension of the line from the origin to the supplier intersects the efficiency frontier. For example, further investment in S2 will result in an efficient output level on the efficiency frontier, which equals the combination of efficient suppliers S6 and S7 with weights 0.46 and 0.36 . Although this paper uses only two output variables, more variables can be considered such as average lead time, relative quality of products, etc.

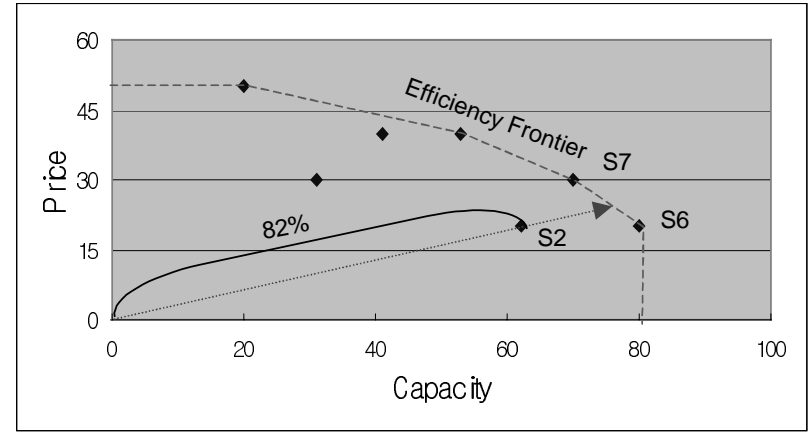

Fig 3 Analysis of the sample supplier data

As shown in Fig 4, ADINS uses an iterative relaxation Contract Net along with DEA for formation of supplierbuyer relationship. An iterative relaxation contract net extends an iterative contract net [8] by allowing participants to relax the constraints imposed in their decision making for a contract. Through an iterative Contract Net, both the buyer and suppliers exchange CFPs (Call For Proposals) and offers (or bids) repeatedly while the buyer gradually relaxes the constraints and the suppliers update bids until an agreement is made. The point of agreement is determined by the intersection of the buyer's constraint space and the suppliers' efficiency frontier. If there is at least one supplier in the intersection, the buyer can contract with any such supplier (e.g. supplier $A$ in $(A)$ ). If not, the buyer can 
contract with a virtual supplier by combining all the suppliers on the vertices of the efficiency frontier (e.g. supplier $V$ in $(B))$, which implies the buyer distributes its orders to the efficient suppliers on the vertices so that the combined order can reach the efficiency frontier. The virtual supplier $\mathrm{V}$ in the example has the output vector $\mathrm{Y}_{\mathrm{v}}=$ $\alpha Y_{a}+(1-\alpha) Y_{b}$, where $0<\alpha<1$ and $Y_{a}$ and $Y_{b}$ represent the output vectors of $\mathrm{A}$ and $\mathrm{B}$ respectively.

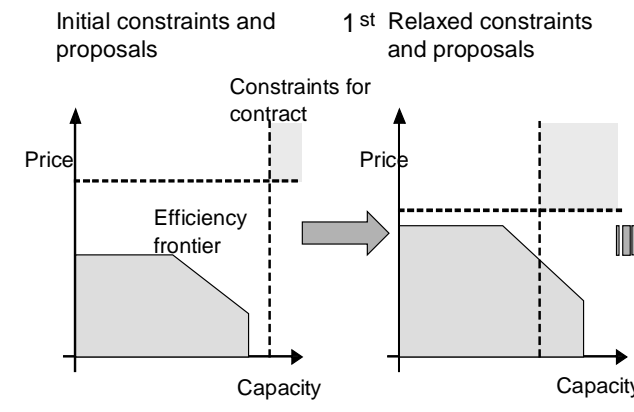

Nth Relaxed constraints and proposals

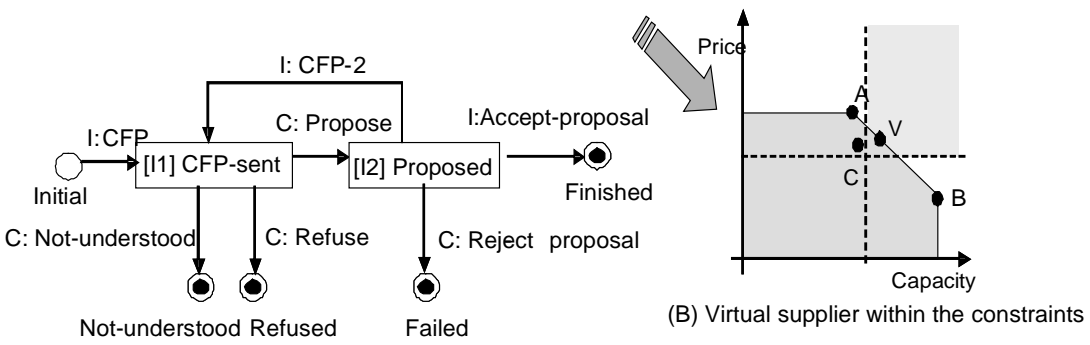

Fig 4 DEA and iterative relaxation Contract Net for forming supplier-buyer relationship

Next, we show two example messages used for the iterative Contract Net. The first message is a CFP from a module plant to a number of cell plants, requesting proposals for the LCD cell product with two constraints: price should be lower than 280 and capacity should be bigger than 40 . As a response, the agent for cell plant 03 sends the second message back to the module plant suggesting a bid with the price 260 and the capacity 30 .

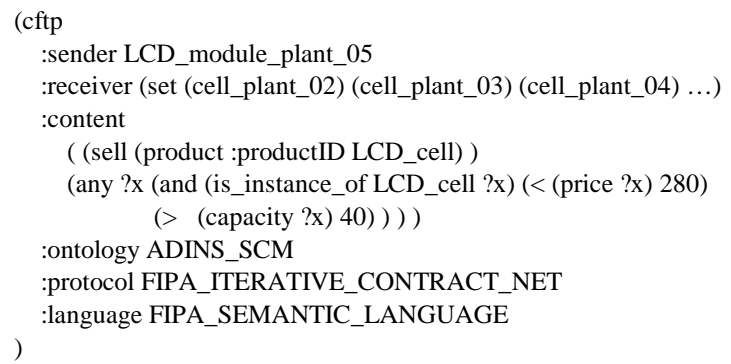

:receiver LCD_module_plant_05

:content

( (sell (product :productID LCD_cell :price 260 :capacity 30) ) ) :ontology ADINS_SCM

:protocol FIPA_ITERATIVE_CONTRACT_NET

:language FIPA_SEMANTIC_LANGUAGE

\subsection{Information Network by Local Information Sharing}

In Fig 1, the example supply chain has two distinct and independent markets. LCD modules are produced by assembling LCD cells, Driver IC, backlights, and other components. LCD cells are again manufactured from other components and material such as glass and colour filters. The LCD modules are provided to the two end markets through two wholesalers. Table 2 provides the definition of symbols for the attributes of the supply chain. 
Table 2 Symbols for the supply chain model

\begin{tabular}{|c|c|}
\hline Symbol & Explanation \\
\hline$N_{i}$ & Node $\mathrm{i}$ in the supply chain \\
\hline$I_{i}^{t}$ & $\begin{array}{l}\text { Inventory level of output products at node } \mathrm{i} \\
\text { at time } \mathrm{t}\end{array}$ \\
\hline$I_{j i} t$ & $\begin{array}{l}\text { Inventory level of material or components } \\
\text { from node } \mathrm{j} \text { held in } \mathrm{i} \text { at time } \mathrm{t}\end{array}$ \\
\hline$L D_{i j}$ & Lead time for delivery from node $\mathrm{i}$ to node $\mathrm{j}$ \\
\hline$L P_{i}$ & $\begin{array}{l}\text { Lead time for production or processing in } \\
\text { node } \mathrm{i}\end{array}$ \\
\hline$O_{i j}{ }^{t}$ & Order issued from node $\mathrm{i}$ to node $\mathrm{j}$ at time $\mathrm{t}$ \\
\hline$P_{i}^{t}$ & Production quantity of node $\mathrm{i}$ at time $\mathrm{t}$ \\
\hline$D_{m}{ }^{t}$ & Demand in market $\mathrm{m}$ at time $\mathrm{t}$ \\
\hline$T_{i j}{ }^{t}$ & $\begin{array}{l}\text { Quantity of delivered products from node } \mathrm{i} \text { to } \\
\text { node } \mathrm{j} \text { at time } \mathrm{t}\end{array}$ \\
\hline$L M_{p i}$ & $\begin{array}{l}\text { Total lead time from node } \mathrm{i} \text { to market } \mathrm{m} \\
\text { through path } \mathrm{p}\end{array}$ \\
\hline$S_{p i}$ & $\begin{array}{l}\text { The market share of the wholesaler in path } \mathrm{p} \\
\text { from node } \mathrm{i}\end{array}$ \\
\hline$D E_{i j}{ }^{t}$ & $\begin{array}{l}\text { Demand estimate for the orders from node } \mathrm{j} \\
\text { to node } \mathrm{i} \text { at time } \mathrm{t}\end{array}$ \\
\hline$D_{p}^{\prime}{ }^{t}$ & $\begin{array}{l}\text { Demand estimate of the market that } \\
\text { corresponds to path } \mathrm{p} \text { at time } \mathrm{t}\end{array}$ \\
\hline$P M_{i}$ & $\begin{array}{l}\text { The set of all paths from node } \mathrm{i} \text { to all } \\
\text { markets. Each path in } P M_{i} \text { is defined as } \mathrm{p}= \\
<\mathrm{m}, 1, \mathrm{BP}>\text {, where } \mathrm{m} \text { is the corresponding } \\
\text { market, } 1 \text { is the total lead time, and } \mathrm{BP} \text { is the } \\
\text { set of neighbouring buyers of node } \mathrm{i} \text { in the } \\
\text { path. }\end{array}$ \\
\hline$B_{i}$ & The set of neighbouring buyers of node $\mathrm{i}$ \\
\hline$S P_{i}$ & The set of neighbouring suppliers of node $\mathrm{i}$ \\
\hline
\end{tabular}

As shown in Fig 1, there are multiple paths for the deliveries from a given node to end markets in the supply chain; node $\mathrm{i}$ in this example has three distinctive paths to markets. We define the information network (IN) of ADINS as $\mathbf{I N}=\left\{\left(\mathrm{N}_{\mathrm{i}}, \mathrm{PM}_{\mathrm{i}}, \mathrm{S}_{\mathrm{pi}}\right) \mid \mathrm{p} \in \mathrm{PM}_{\mathrm{i}}, \mathrm{i}=1, \ldots, \mathrm{n}\right.$, where $\mathrm{n}$ is the total number of nodes in a supply chain $\}$. Thus, an information network is the set of all the nodes, their paths to markets, and the market share of the final suppliers in each path in a supply chain. The IN for the example LCD supply chain is produced using the algorithm shown in Fig 5.

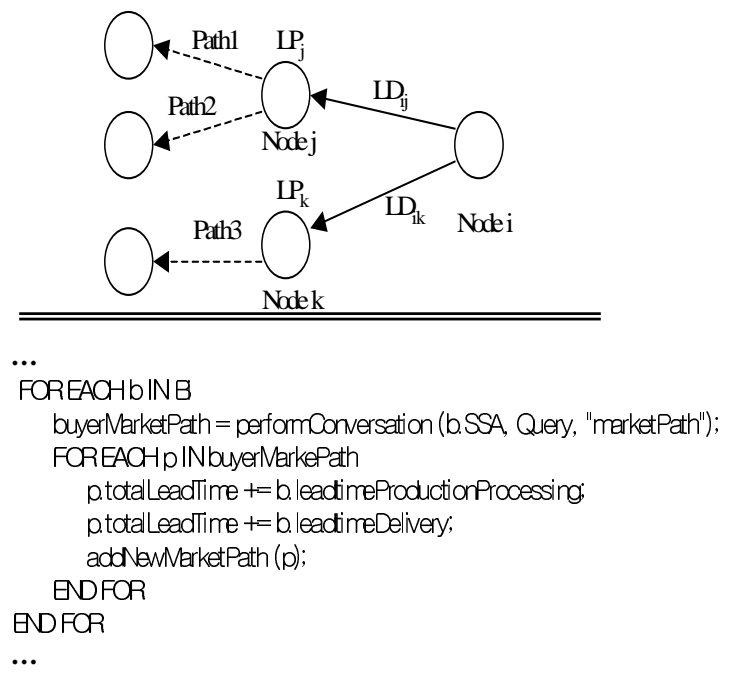

Fig 5 The paths to markets from a node and the algorithm for updating the information network

Using the information network, each node i can estimate demands incoming from each neighbouring buyer $\mathrm{j}$ using the formula (1). Estimates are calculated by the summation of end market demands in each path multiplied by the market share of the last supplier in the path. Using this formula, all nodes can synchronize their estimation without the possible distortion of demand information along the paths from markets, and moreover, without the help from any central control entities.

$$
D E_{i j}{ }^{t}=\sum_{p \in P M_{j}} S_{p i} D_{p}^{\prime L M_{p i}}
$$

\subsection{Behaviour of Agents in ADINS}

In an ADINS, each company in a supply chain has four agents as described in Section 3.1. In order to develop an application system using ADINS, we need to specify clearly the behaviours of each agent including the trail of states they go through, the states wherein the agent communicates with other agents both inside and outside of a company boundary, and the conditions that should be considered for a transition from one state to another. This paper uses Petri-Net for this purpose as shown in Fig 6 (see [11] for another example of Petri-Net based modelling of agent behaviour). The numbered arrows (1) (6) represent the collaborations between two agents in different companies. 
Table 3 Information network for the example LCD supply chain (for selected nodes)

\begin{tabular}{llllll}
\hline $\begin{array}{l}\text { Node } \\
\#(\mathrm{i})\end{array}$ & Path \# (p) & $\begin{array}{l}\text { Market } \\
\#(\mathrm{~m})\end{array}$ & $\begin{array}{l}\text { Nodes in the } \\
\text { Path } \mathrm{p}\end{array}$ & Total Lead Time $\left(\mathrm{LM}_{\mathrm{pi}}\right)$ & $\begin{array}{l}\text { Market Share } \\
\text { Associated with } \mathrm{p}\left(\mathrm{S}_{\mathrm{pm}}\right)\end{array}$ \\
\hline 6 & 1 & $1-3-6$ & $\mathrm{LD}_{31}+\mathrm{LP}_{3}+\mathrm{LD}_{63}$ & $\mathrm{~S}_{3}$ \\
\hline 7 & 1 & 0 & $0-2-4-7$ & $\mathrm{LD}_{20}+\mathrm{LP}_{2}+\mathrm{LD}_{42}+\mathrm{LP}_{4}+\mathrm{LD}_{74}$ & $\mathrm{~S}_{1}$ \\
\hline 8 & 1 & 1 & $1-2-4-7$ & $\mathrm{LD}_{21}+\mathrm{LP}_{2}+\mathrm{LD}_{42}+\mathrm{LP}_{4}+\mathrm{LD}_{74}$ & $\mathrm{~S}_{2}$ \\
\hline 9 & 1 & 0 & $0-2-5-8$ & $\mathrm{LD}_{20}+\mathrm{LP}_{2}+\mathrm{LD}_{52}+\mathrm{LP}_{5}+\mathrm{LD}_{85}$ & $\mathrm{~S}_{1}$ \\
\hline & 1 & 1 & $1-2-5-8$ & $\mathrm{LD}_{21}+\mathrm{LP}_{2}+\mathrm{LD}_{52}+\mathrm{LP}_{5}+\mathrm{LD}_{85}$ & $\mathrm{~S}_{2}$ \\
\hline & 1 & 0 & $0-2-5-9$ & $\mathrm{LD}_{20}+\mathrm{LP}_{2}+\mathrm{LD}_{52}+\mathrm{LP}_{5}+\mathrm{LD}_{95}$ & $\mathrm{~S}_{1}$ \\
\hline
\end{tabular}

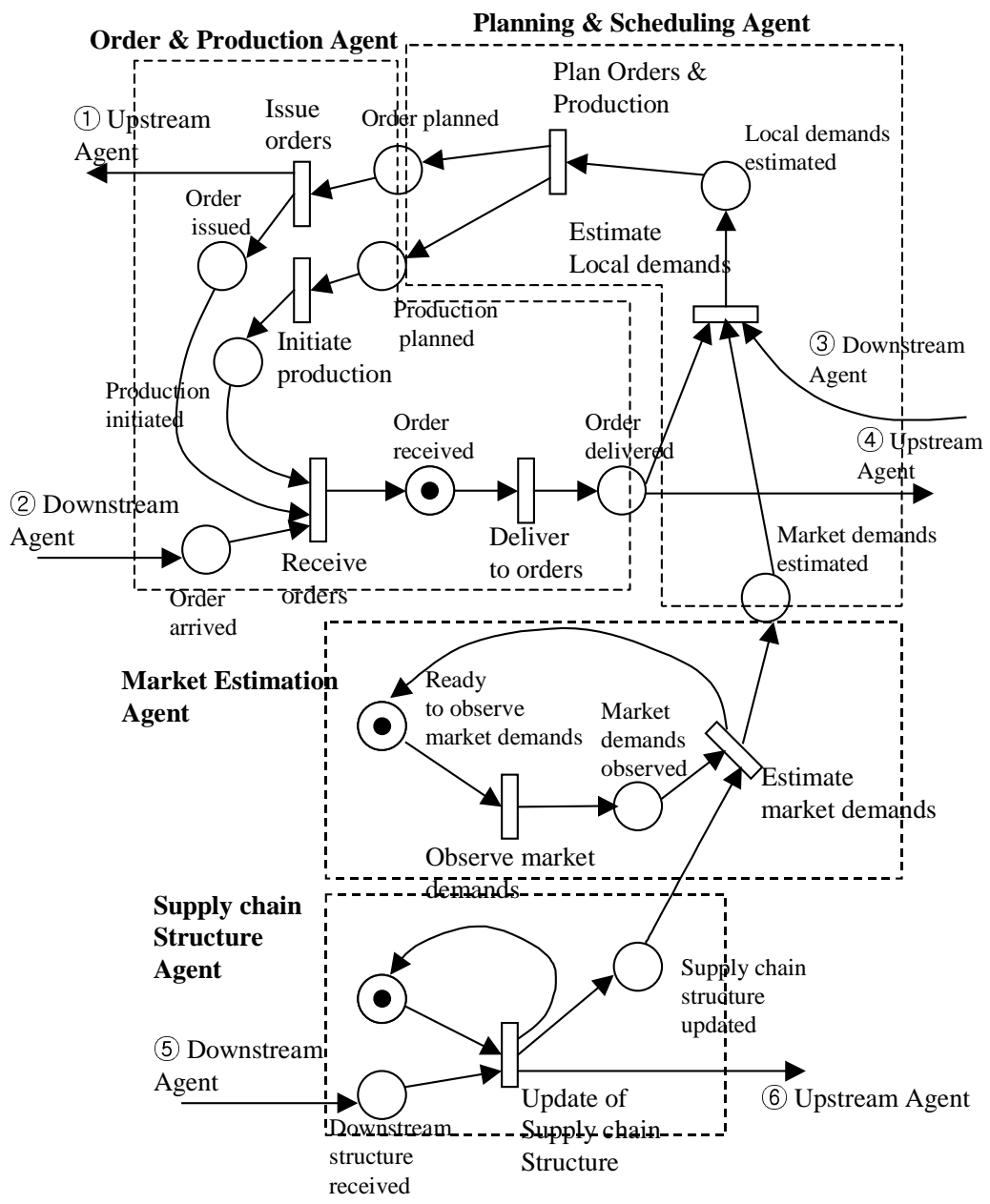

Fig 6 A Petri-Net based model of the behaviours of participating agents in ADINS. 
A. OPA (Order \& Production Agents): An OPA initiates a production and issues orders according to the plans generated by an internal PSA (at Order Planned and Production Planned states). It also receives orders from the OPAs of direct buyer companies (2) Order arrived) and sends orders to the OPAs of direct supplier companies (1) Issue orders). After handling incoming orders, it shares the inventory level information of its company with the PSAs of its direct supplier companies (4) Order delivered).

B. PSA (Planning \& Scheduling Agent): A PSA makes production plans and order plans and passes them to the internal OPAs (at Order Planned and Production Planned states). It collaborates with the OPAs of its buyers to utilize their inventory information in generating the plans (3) Estimate local demands). It also collaborates with the internal MEA to receive demand estimate information on the end markets (at Market Demands Estimated).

C. MEA (Market Estimation Agent): A MEA observes market demands directly, not relying on intermediate nodes, (at Observe Market Demands state) and estimates the demand pattern that will be propagated to its company in the future through the paths to markets. A MEA collaborates with a SSA to acquire the paths to markets (at Estimate Market Demands state).

D. SSA (Supply chain Structure Agent): A SSA receives information on a supply chain structure such as the paths to markets, from the SSAs of neighbouring downstream companies (5) Downstream structure received), and propagates updated structure to the SSAs of neighbouring upstream companies (6) Update of supply chain structure), thus constructing the information network (SSA is also used for supply chain formation by iterative Contract-net but this part is not included in the figure for simplicity).

Based on the Petri-Net model, we describe the detailed behaviours of each agent using pseudo codes in Fig 7. The transitions in the Petri-Net model are easily transformed to primitive operations such as 'initiateProduction' or 'deliverToOrder' and the communication points can be also expressed using the conversational function 'performConversation ( )'.

In Fig 7, an OPA first performs conversation with a PSA using the FIPA Query protocol to receive order and production plans. And then, it issues orders to neighbouring buyers using FIPA Request protocol. And then, an actual production is initiated according to the plans and orders are delivered to neighbouring suppliers based on the order information acquired by another conversation using the Request protocol.

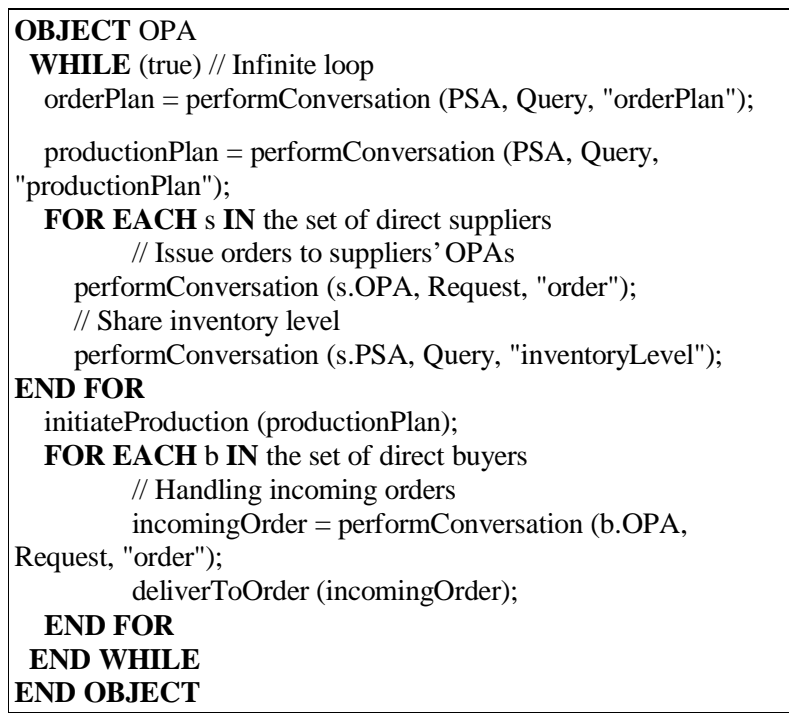

Fig 7 Pseudo code for describing the behaviour of OPAs.

Table 4 gives the summary of the communications among agents: protocols, involved participants, and exchanged information. As shown in the table, FIPA's Request and Query [6][7] protocols are used for each of the conversations that could be identified from the Petri-Netbased behaviour model.

\section{Discussion and Conclusion}

\subsection{Discussion}

The contribution of this paper is to propose an agent based approach to improve the global efficiency of a supply chain by enabling participating companies to form a reasonably efficient supply chain dynamically and to minimise bullwhip effects in a supply chain via information sharing among cooperative agents.However, limitations exist with the suggested approach. First, although DEA and iterative relaxation Contract Net were suggested for dynamic formation of supply chains, this paper does not suggest specific bidding strategies for each participating agents. We regard game-theoretic analysis of possible negotiation strategies or applying optimisation techniques such as the genetic algorithm as being out of the scope of this paper and, thus, a further research issue. Second, although we used a real LCD supply chain model from industry to show practicality of ADINS, the verification of the approach is needed. A simulation analysis is an alternative for the verification to show the effectiveness of ADINS. Third, the 
approach assumes that agents can observe end market demands, which may be unrealistic in some cases. Although we admit that this is a practical limitation in generalizing the ADINS approach, we expect the rapid development of technology for gathering point-of-sales (POS) data using technologies such as RFID (Radio Frequency IDentification) is making this assumption more realistic. Also, it is sometimes possible to observe end market demands indirectly using available market demand data of related products (e.g., observing the demands for PDAs and mobile phones for indirect estimation of demands for LCD modules).

Despite the above limitations, ADINS is distinguished from other agent-based approaches for supply chain management in that it provides more practical features such as local information sharing for constructing information networks, utilizing DEA for selecting relatively efficient suppliers, and reducing bullwhip effects in a supply chain by using social interactions between pro-active agents to maximise the performance of the whole supply chain.

\subsection{Conclusion}

This paper suggested data envelopment analysis with an iterative relaxation Contract Net for formation of dynamic supply chains and an information network that enables companies to estimate future demands from multiple market paths in a synchronized way. A Petri-Net based behaviour model for each agent was developed to clarify the states, transitions, and communication requirements of agents and also to facilitate the derivation of concrete procedures for agent behaviours that can be used for actual development of agent systems. In order to show the practical feasibility of the approach, the conversations among agents were also modelled with FIPA's standard interaction protocols and messages and a prototype system was constructed using a FIPA-compliant agent platform JADE [3].

Although there are some limitations as mentioned in the previous sub-section, we believe that this paper has contributed to proving the ever-growing potential of agent technology for practical supply chain management where analytic or optimisation results from simple supply chains cannot be easily applied or global information sharing or central coordination is impossible. Further research issues include the full implementation of ADINS, relaxing the assumptions on supply chains, and analysing the bidding strategies for the iterative relaxation Contract Net in the supply chain formation stage.

Table 4 Communication among agents: protocol, participants, and exchanged information

\begin{tabular}{llll}
\hline Conversation Name & Protocol & $\begin{array}{l}\text { Participants (Initiator } \rightarrow \text { Counterpart) } \\
{[\mathrm{U}]: \text { Upstream, [D]: Downstream }}\end{array}$ & Exchanged information \\
\hline $\begin{array}{llll}\text { Query Order Plan } \\
\text { Query Production Plan }\end{array}$ & Query & OPA $\rightarrow$ PSA & orderPlan \\
\hline $\begin{array}{llll}\text { Share Inventory Level } \\
\text { Issue Order Request }\end{array}$ & Query & {$[\mathrm{U}]$ PSA $\rightarrow[\mathrm{D}]$ OPA } & productionPlan \\
\hline $\begin{array}{l}\text { Query Market } \\
\text { Demands }\end{array}$ & Query & PSA $\rightarrow$ MEA $\rightarrow[U]$ OPA & inventoryLevel \\
\hline $\begin{array}{l}\text { Query Paths to } \\
\text { Markets }\end{array}$ & Query & MEA $\rightarrow$ SSA & Order \\
\hline $\begin{array}{l}\text { Share Supply Chain } \\
\text { Structure }\end{array}$ & Query & {$[\mathrm{U}]$ SSA $\rightarrow[\mathrm{D}]$ SSA } & marketDemands \\
\hline
\end{tabular}

\section{Acknowledgements}

The authors acknowledge the help from Youngshik Lee for his kind efforts in designing the supply chain model and for giving insights about the problems in practical supply chains.

\section{References}

1. Banker R D and Charnes A: 'An introduction to data envelopment analysis with some of its models and their uses', Research in Governmental and Nonprofit Accounting, JAI Press. 5, pp 125-163 (1989). 
2. Barbuceanu M, Teigen R., and Fox M S: 'Agent Based Design and Simulation of Supply Chain Systems', Proceedings of the 6th Workshop on Enabling Technologies Infrastructure for Collaborative Enterprises (WET-ICE '97), pp 18 - 20 (1997).

3. Bellifemine F, Caire G, Poggi A, Rimassa G: JADE - A White Paper', Special Issue on Jade of Telecom Italia Lab Journal EXP, 3, No 3, pp 6 - 19 (2003).

4. Chen F, Drezner Z, Ryan J K, and Simchi-Levi D: 'Quantifying the Bullwhip Effect in a Simple Supply Chain: The Impact of Forecasting Lead Times, and Information', Management Science, 46, No 3, pp 436 443 (2000).

5. FIPA web site - http://www.fipa.org/.

6. FIPA00026: FIPA Request Interaction Protocol Specification, Foundation for Intelligent Physical Agents, 2000 - http://www.fipa.org/specs/fipa00026/.

7. FIPA00027: FIPA Query Interaction Protocol Specification. Foundation for Intelligent Physical Agents, 2000 - http://www.fipa.org/specs/fipa00027/.

8. FIFA00030, FIPA Iterated Contract Net Interaction Protocol Specification. Foundation for Intelligent Physical Agents, 2001, http://www.fipa.org/specs/fipa00030/.

9. Fox M S, Barbuceanu M, and Teigen R: 'AgentOriented Supply-Chain Management', International Journal of Flexible Manufacturing Systems, 12, No 2/3, pp 165-188 (2000).

10. Kim J B: 'Multi-Component Contingent Auction (MCCA): A Procurement Mechanism for Dynamic Formation of Supply Networks', Proceedings of International Conference on e-Commerce, Pittsburgh, USA, (2003).

11. Kwon O B and Lee J J: 'A multi-agent intelligent system for efficient ERP maintenance', Expert Systems with Applications, 21, No 4, pp 191-202 (November 2001).

12. Mondal S and Tiwari M K: 'Formulation of mobile agents for integration of supply chain using the KLAIM concept', International Journal of Production Research, 41, No 1, pp 97-119 (2003).

13. Nissen M E: 'Agent-based Supply Chain Disintermediation versus Re-intermediation: Economic and Technological Perspectives', International Journal of Intelligent Systems in Accounting, Finance, \& Management, 9, pp 237-256 (2000).

14. Pontrandolfo P, Gosavi A, Okogbaa O G, and Das T K: 'Global supply chain management: a reinforcement learning approach', International Journal of Production Research, 40, No 6, pp 1299-1317 (2002).

15. Qinghe H, Kumar A, and Shuang Z: 'A biding decision model in multi-agent supply chain planning', International Journal of Production Research, 39, No 15, pp 3291-3301 (2001).

16. Shen W, Kremer R, Ulieru M, and Norrie D: 'A collaborative agent-based infrastructure for Internetenabled collaborative enterprise', International Journal of Production Research, 41, No 8, pp 1621-1638 (2003).

17. Sun J and Sadeh N M: 'Dynamic supply chain formation: integrating multi-attribute auctions and finite capacity scheduling', Proceedings of the 4th ACM conference on Electronic commerce, San Diego, CA, USA, pp 244-245 (2003).

18. Swaminathan J M: 'Modeling supply chain dynamics: A Multiagent Approach', Decision Sciences, 29, No 3, pp 607-632 (1997).

19. $\mathrm{Yu} \mathrm{Z}$, Yan $\mathrm{H}$, and Cheng $\mathrm{T} \mathrm{C}$ E: 'Benefits of information sharing with supply chain partnerships', Industrial Management \& Data Systems, 101, No 3, pp 114-119 (2001). 